\title{
Development of a poly-L-lactide salivary duct stent
}

\author{
YI-FANG DING ${ }^{1}$, HOW TSENG ${ }^{2,3}$, CHIN-HUI SU ${ }^{4,5}$, CHIEN-CHENG TAI $^{2}$, YUAN-YI WU ${ }^{2}$, \\ CHENG-JI HAUNG ${ }^{2}$, CHENG-SHEN LEE ${ }^{2}$ and SHIH-HAN HUNG ${ }^{4,6}$
}

\begin{abstract}
${ }^{1}$ Department of Otolaryngology, Taipei Medical University Wan-Fang Hospital; ${ }^{2}$ Graduate Institute of Medical Sciences; Departments of ${ }^{3}$ Biochemistry and Molecular Cell Biology and ${ }^{4}$ Otolaryngology, College of Medicine, Taipei Medical University; ${ }^{5}$ Department of Otorhinolaryngology, Mackay Memorial Hospital; ${ }^{6}$ Department of Otolaryngology,
\end{abstract}

Taipei Medical University Hospital, Taipei 110, Taiwan, R.O.C.

Received June 15, 2018; Accepted October 12, 2018

DOI: $10.3892 / \mathrm{etm} .2019 .7308$

\begin{abstract}
Obstructive salivary gland diseases are common conditions that arise following the disruption of the secretary ductal system and usually results in the swelling and pain of the affected gland(s). There has been an increase in the use of sialendoscopy for the treatment and diagnosis of obstructive salivary gland infection. If damage occurs to a duct or papilla following sialendoscopy, a stent may be necessary to prevent restenosis and for maintaining the salivary duct open after complete sialendoscopy. Currently, there are only non-biodegradable salivary duct stents available. The aim of the current study was to establish a methodology for the fabrication of a biodegradable poly-L-lactide (PLLA) salivary duct stent and to examine its function in an animal model. In the current study, PLLA was used to fabricate a salivary duct stent, which was compared with other commercially available non-biodegradable products. The mechanical tests revealed that the tensile strength of the PLLA stent was similar to that of the commercially available non-biodegradable stents. The Young's modulus, which measures the stiffness of a solid material, was significantly higher for the PLLA stent compared with the commercially available non-biodegradable stents. In addition, the current study demonstrated that the PLLA salivary duct stent was easily used with current sialendoscopy techniques, allowing accurate stent placement in an animal model.
\end{abstract}

\section{Introduction}

There has been an increase in the use of sialendoscopy for the treatment and diagnosis of obstructive salivary gland infection (1). In cases where ductal stenosis has occurred, salivary duct stent placement appears to be one of the main treatment

Correspondence to: Professor Shih-Han Hung, Department of Otolaryngology, College of Medicine, Taipei Medical University, 250 Wuxing Street, Taipei 110, Taiwan, R.O.C.

E-mail: seedturtle@gmail.com

Key words: sialendoscopy, stent, biodegradable, poly-L-lactide options $(2,3)$. A previous study demonstrated that salivary duct stent placement using hypospadias silastic and pediatric feeding tubes (size 5-Fr) was successfully achieved and maintained for approximately two weeks before displacement (4). Although stenting is routinely used in clinical practice, a common limitation associated with ductal stents is the relatively short duration of stent implantation following surgery. Typically ductal stents are expected to remain in the salivary duct for only 1-2 weeks until they are removed during follow-up visits, or earlier, if the securing sutures break prematurely (4). Even with a short duration of stent implantation, complications including iatrogenic stenosis can occur due to the undesired mechanical contact between the ductal wall and stent edge (5). Furthermore, there is no recommended duration of stent implantation for salivary ductal stenosis. By contrast, intravascular stents are often placed for months, even when using bioresorbable vascular scaffolds (6). Beilvert et al (7) demonstrated the use of a new resorbable starch-based shape-memory salivary duct stent in an animal model, for the treatment of salivary ducts under sialendoscopic surgery. However, the resorbable starch-based stents were rapidly hydrolyzed in simulated saliva, resulting in undesired stent placement.

The aim of the current study was to establish a methodology for the fabrication of a PLLA salivary duct stent and to examine its function in a porcine head model.

\section{Materials and methods}

PLLA stent fabrication. PLLA (Poly L-lactide; molecular weight, $140 \mathrm{kDa}$; glass transition temperature, $60-62^{\circ} \mathrm{C}$; Biotech One Inc., Taipei City, Taiwan). was dissolved in dichloromethane (Burdick \& Jackson $^{\mathrm{TM}}$; Honeywell Research Chemicals, NJ, United States) and stirred for $30 \mathrm{~min}$ at $25^{\circ} \mathrm{C}$ with a final concentration of $15 \%(\mathrm{w} / \mathrm{v})$. For stent fabrication, a $15 \mathrm{~cm}$ stainless steel rod with a $1.1 \mathrm{~mm}$ outer diameter was immersed in the PLLA solution and then quickly withdrawn. The PLLA-coated rod was placed on a custom-made rotor at $20 \mathrm{rpm}$ to ensure even distribution of the PLLA solution on the surface of the rod. The PLLA-coated rods were left to dry overnight at room temperature. The PLLA tube was easily removed from the stainless rod and cut into different lengths depending on its clinical application (Fig. 1A). Using a sialendoscope, a silicon tube with an inner diameter of $1.2 \mathrm{~mm}$ and an outer diameter of $1.4 \mathrm{~mm}$ was 
pre-inserted proximally to the stent and used as a stent 'pusher' during application (Fig. 1B).

Mechanical properties. The fabricated PLLA salivary duct stent was compared with three commercially available non-biodegradable stents: $14 \mathrm{G}$ needle cannula (B. Braun Melsungen AG, Hessen, Germany), feeding tube (Symphon Medical Technology Co., Ltd., New Taipei City, Taiwan; size 5-Fr) and hypospadias silastic tube (Symphon Medical Technology Co., Ltd.; Fig. 2). The mechanical characteristics were measured using a universal LFPlus digital testing machine (Lloyd Instruments; AMETEK, Inc., Berwyn, PA, USA) to measure stretch and elongation. The length of the tested stents was set to $4 \mathrm{~cm}$. Between two gripper arms, the tube axis was aligned with the stretching axis. In addition, the Young's modulus (GPa) was calculated from the linear slope of a stress-strain curve for each tested stent. Testing was performed in triplicate.

Animal model. In this study, the porcine head model was used. The oral-maxillofacial region in pigs is most similar to humans with regard to anatomy, development, physiology and pathophysiology (8). Pig heads were obtained from a local pork supplier. Following the removal of the upper jaw and buccal mucosa, the tongue was retracted providing full exposure of Stensen's and Wharton's ductal papillae.

Sialendoscopy set-up. Sialendoscopy was performed using a semi rigid $0^{\circ}$ Miniature Straight Forward Telescope (11573A; Karl Storz, Tuttlingen, Germany), outer diameter $1.1 \mathrm{~mm}$, working length $12 \mathrm{~cm}$, working channel diameter $0.45 \mathrm{~mm}$ and irrigation channel diameter $0.25 \mathrm{~mm}$.

Sialendoscopy. Following identification of the papillae, the stent-sheathed sialendoscope was inserted into the opening of the salivary gland duct. The scope was directed to the site of stenosis (Fig. 3A). At the site of stenosis, the silicon tube stent 'pusher' was used to facilitate stent placement (Fig. 3B). The scope with the silicon 'pusher' attached, was gently withdrawn, leaving the salivary duct stent in place (Fig. 3C).

Statistical analysis. All experiments were performed in triplicate and data are presented as the mean \pm standard deviation. A one-way analysis of variance followed by Tukey's post hoc test was used to analyze the differences in mechanical properties with SPSS v.16 software (SPSS, INC., Chicago, IL, USA). $\mathrm{P}<0.05$ was considered to indicate a statistically significant difference.

\section{Results}

Mechanical analysis. The mechanical properties of the PLLA stent, hypospadias silastic tube, feeding tube (size 5-Fr) and $14 \mathrm{G}$ needle cannula are shown in Table I. The elongation stress-strain curves indicate that the PLLA stent is considerably stiffer than commercially available tubes, resulting in fewer dynamic shape changes under similar loads (Fig. 4). The tensile strength of the PLLA stent was similar to that of the commercially available stents. The Loading (N) for the PLLA stent was lower compared with commercially available stents.

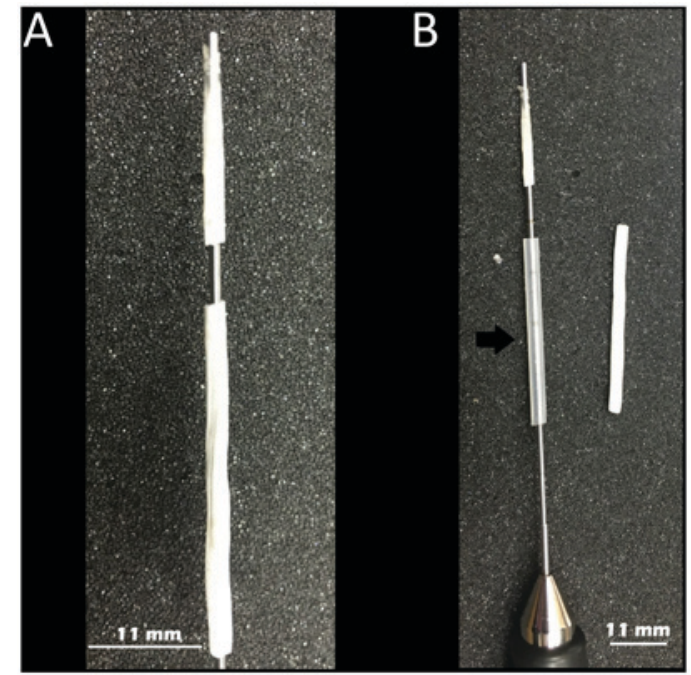

Figure 1. Clinical application of the PLLA stent. (A) The PLLA tube can be easily removed from the stainless rod and cut into different lengths. (B) A silicon tube with an inner diameter of $1.2 \mathrm{~mm}$ and an outer diameter of $1.4 \mathrm{~mm}$ was pre-inserted proximally to the stent and used as a stent 'pusher' during application.

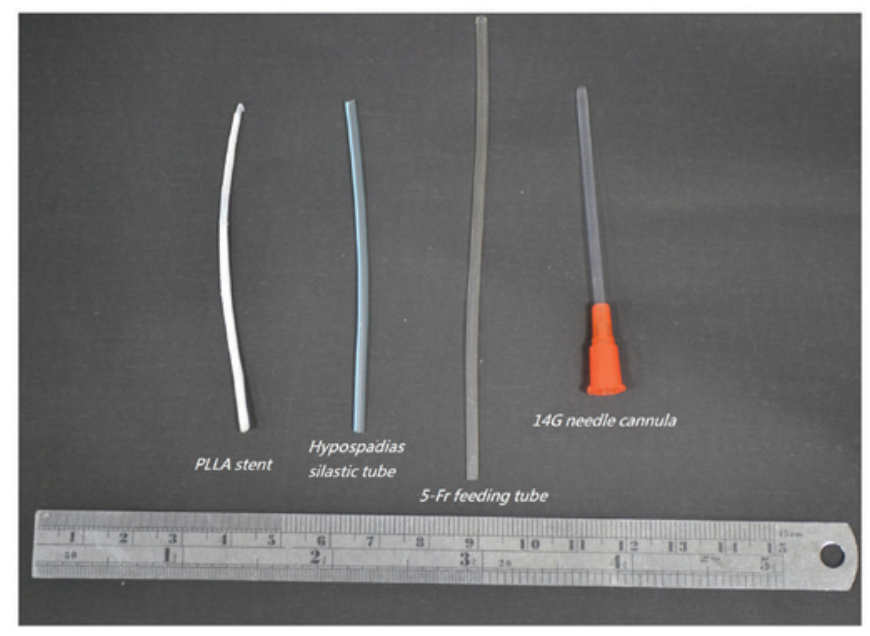

Figure 2. PLLA and commercial non-biodegradable stents. The fabricated PLLA salivary duct stent was compared with three commercially available non-biodegradable stents: (left to right) hypospadias silastic tube, feeding tube (size 5-Fr), and 14G needle cannula.

The Young's modulus, which was calculated from the linear slope of the stress-strain curve, was markedly higher for the PLLA stent compared with the commercially available stents $(\mathrm{P}<0.01$; Fig. 5).

Functional evaluation of PLLA salivary duct stent placement. Following identification of the papilla, the main salivary gland duct could be easily identified. Post-placement sialendoscopic evaluations revealed that the stent placement inside the salivary gland ductal lumen was secured in place and allowed continuous irrigation (Fig. 6, arrow head).

\section{Discussion}

In the current study, fabrication of a PLLA-based biodegradable salivary duct stent and its functional application using 

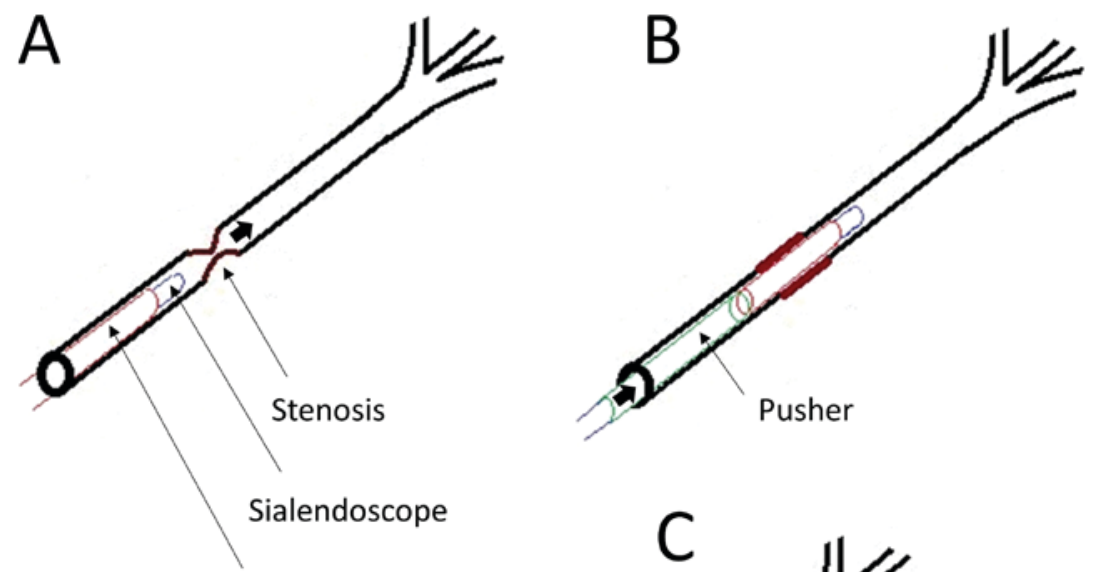

PLLA Stent

Figure 3. Schematic diagram of the sialendoscopy procedure using the fabricated PLLA stent. (A) Following identification of the papillae, the stent-sheathed sialendoscope (blue) was inserted into the opening of the salivary gland duct and directed to the site of stenosis. (B) At the site of stenosis, the silicon tube stent 'pusher' (green) was used to facilitate the distal end of the stent (red) placement at the site of stenosis. (C) The silicon 'pusher' and the scope were gently withdrawn, leaving the salivary duct stent in place at the site of stenosis.

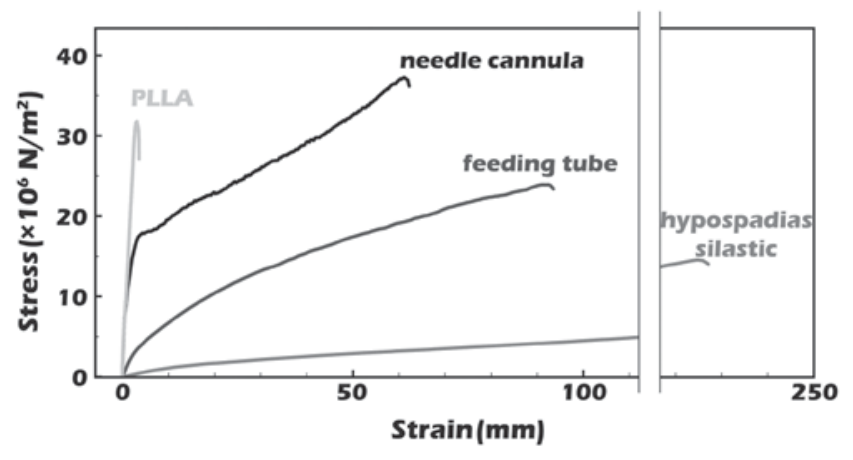

Figure 4. Elongation stress-strain curves. The PLLA stent appears to be harder than other commercially available non-biodegradable stents. PLLA, poly-L-lactide.

mechanical tests was established in a porcine head model. The PLLA stent had a significantly higher Young's modulus compared with commercially available non-biodegradable stents, which suggest that it has a greater collapse-resisting strength. In addition, the current study demonstrated that the PLLA salivary duct stent was easily used with current sialendoscopy techniques, allowing accurate stent placement in an animal model with a relatively small ductal lumen.

Salivary duct stenosis is a well-known condition in which the duct of a major salivary gland responsible for saliva flow out of the salivary gland parenchyma is narrowed, leading to a decreased lumen, which compromises the secretory function of the gland (9). Previous studies revealed that salivary duct obstruction can occur as a result of trauma, calculi, autoimmune disorders, radiation, stenosis or fibro mucinous

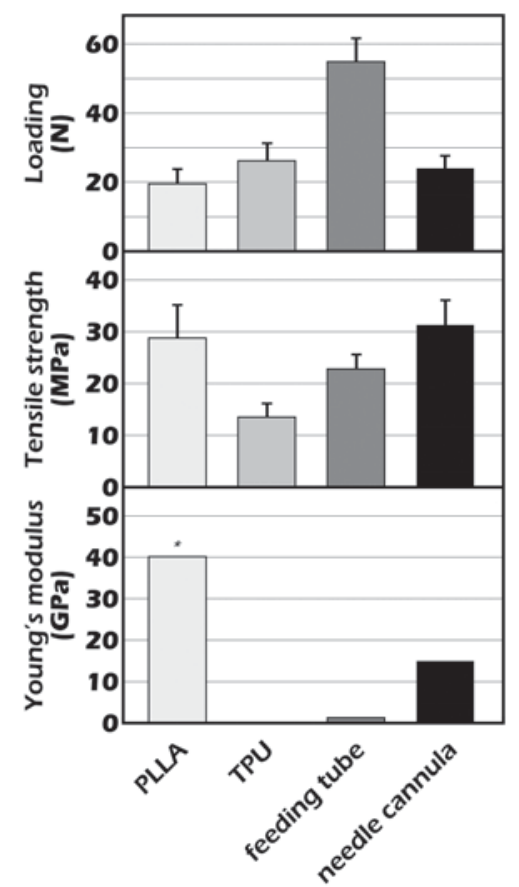

Figure 5. Mechanical properties of PLLA and commercial non-biodegradable stents. The tensile strength of the PLLA stent was similar to that of the commercially available stents. The Young's modulus was significantly higher for the PLLA stent compared with the commercially available stents. " $\mathrm{P}<0.01$ vs. TPU, feeding tube and needle cannula. PLLA, poly-L-lactide.

plugs, which result in salivary stasis a predisposing factor to bacterial infection $(10,11)$. Once a ductal stenosis has formed, it is initially managed through ductal dilatations using probes 
Table I. Mechanical properties of PLLA and commercial non-biodegradable stents.

\begin{tabular}{lcccccrr}
\hline Material & $\begin{array}{c}\text { Outer } \\
\text { diameter } \\
(\mathrm{mm})\end{array}$ & $\begin{array}{c}\text { Inner } \\
\text { diameter } \\
(\mathrm{mm})\end{array}$ & $\begin{array}{c}\text { Wall } \\
\text { thickness } \\
(\mathrm{mm})\end{array}$ & $\begin{array}{c}\text { Area } \\
\left(\mathrm{mm}^{2}\right)\end{array}$ & $\begin{array}{c}\text { Loading } \\
(\mathrm{N})\end{array}$ & $\begin{array}{r}\text { Tensile } \\
\text { strength } \\
(\mathrm{MPa})\end{array}$ & $\begin{array}{r}\text { Young's } \\
\text { modulus } \\
(\mathrm{GPa})\end{array}$ \\
\hline PLLA & 1.391 & 1.136 & 0.177 & 0.6755 & $19.5 \pm 4.24$ & $28.8 \pm 6.27$ & 40.12 \\
Hypospadias silastic tube & 2.081 & 1.363 & 0.359 & 1.9421 & $26.2 \pm 5.05$ & $13.5 \pm 2.60$ & 0.13 \\
Feeding tube (size 5-Fr) & 2.128 & 1.209 & 0.459 & 2.4081 & $54.9 \pm 6.65$ & $22.8 \pm 2.76$ & 1.30 \\
14G needle cannula & 1.527 & 1.163 & 0.182 & 0.7678 & $24.0 \pm 3.61$ & $31.3 \pm 4.71$ & 15.00 \\
\hline
\end{tabular}

PLLA, poly-L-lactide.

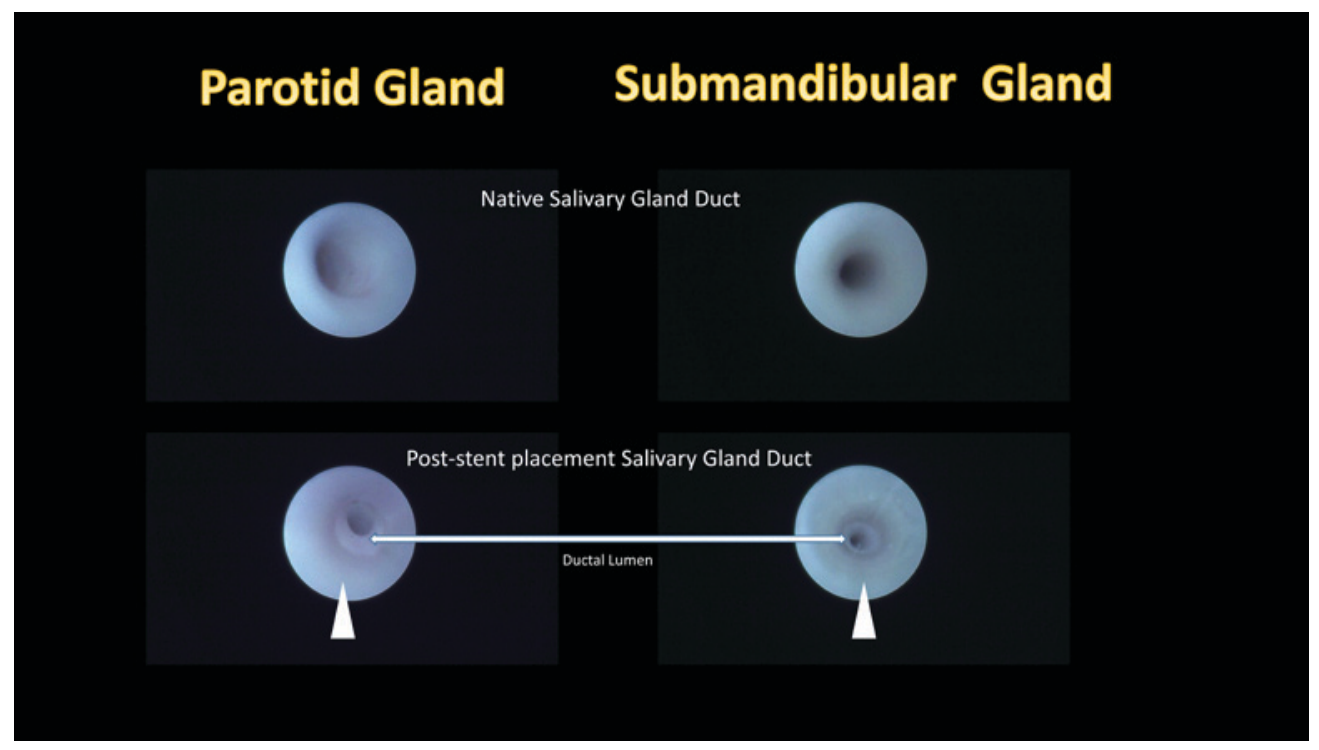

Figure 6. Post-placement sialendoscopic evaluations. Following identification of the papilla, the main salivary gland duct could be easily identified (left and right upper). Post-placement sialendoscopic evaluations revealed that the stent placement inside the salivary gland ductal lumen was secured in place allowing continuous irrigation (arrow head).

or balloons (12). Unsatisfactory dilatation of the salivary duct stenosis can sometimes result in total gland removal (13). For the management and treatment of salivary duct stenosis, new treatment options have emerged as a result of the introduction of an endoscopic approach to salivary gland ductal pathologies, known as sialendoscopy.

Since its introduction more than a decade ago by Professor Francis Marchal, interventional sialendoscopy has become the predominant therapeutic approach for the management of obstructive salivary disorders $(14,15)$. During this time, the procedure has evolved from its initial use for simple diagnostic observation to the integration of various treatment modalities. In 2009, Koch et al (16) demonstrated that sialendoscopy-based diagnosis is a first choice diagnostic method, which enabled the direct classification of parotid duct stenosis, which provided additional information and a more effective treatment. Once stenoses are located, balloon sialoplasty is commonly used to dilate the stenotic site (15). Following balloon sialoplasty, surgeons have the option to leave the site alone or to stent it with a tube for a certain period of time which prevents the site from collapsing again. In 2012, Lempe et al (2) demonstrated the successful use of a stent for the repair of an injured parotid duct in a thoroughbred colt horse. In addition, Kopeć et al (17) revealed the use of vascular radiologic examination catheters as salivary duct stents, whilst Koch et al (18) reported the use of polyurethane stents with different diameters (Fr. 4.5-6.0) based on the size of the scope. A previous study demonstrated the use of commercially available custom-made stents for sialendoscopy (19). Furthermore, Kopeć et al (17) reported the treatment of 69 stenoses in 51 patients with stent insertion following stenosis dilatation. The stent was placed for 14-21 days before removal, and in total seven patients remained partially symptomatic and four patients had no improvement. A previous study demonstrated the use of hypospadias silastic tubes and pediatric feeding tubes (size 5-Fr) as post-sialendoscopy stents (4), which were maintained for approximately 2 weeks. Early dislocation was observed following the premature breaking of the securing sutures. It would therefore be beneficial to have a salivary duct stent that could be placed exactly at the site of stenosis without the need for removal, and which could last for a longer period of time to allow stabilization at the dilated stenosis site. Beilvert et al (7) developed a resorbable shape-memory starch-based stent for the treatment of salivary ducts under sialendoscopic surgery. Potato starch and high-amylose-content maize starch (Eurylon 7) were 
used as materials to fabricate the stents used in the study. Beilvert et al (7) demonstrated that the stents made from plasticized starch had the required shape-memory properties to be used as self-deploying stents, however, the stents were rapidly hydrolyzed in simulated saliva. In this previous study, starch was used to fabricate the salivary duct stents as this would allow salivary amylase to naturally degrade the stent over time, however, the integrity of the stents was lost during the first $24-48 \mathrm{~h}$ of the study. A previous study demonstrated the use of PLLA biodegradable stents for the use of resorbable endovascular stenting (20). A PLLA stent has the potential to last for a few months or longer, but PLLA degradation may activate local inflammatory responses (21). However, the normal flow of saliva may remove any molecules released during PLLA degradation, thereby reducing the impact to the salivary ductal wall (7).

In the current study, the elongation stress-strain curves demonstrated that the PLLA stent appears to be stiffer than the commercially available non-biodegradable tubes, resulting in fewer dynamic shape changes under similar loads. A harder stent may increase the degree of discomfort for patients. However, a previous study revealed that the feeding tube, which is harder than the hypospadias silastic tube, has a lower rate of irritation and obstructive complications (4). These results suggest that the material used for the fabrication of the salivary duct stent may not need to be soft; it may be that a harder stent has a greater resistance to the collapsing force. Furthermore, the diameter of the PLLA stent was the smallest of all the stents tested. This was designed to fit the outer diameter of the sialendoscope to allow a smooth installation and passage to the site of stenosis. The advantage of having a larger diameter stent would be an increase in the rate of saliva flow and more secure stent localization after placement. However, a larger diameter stent increases the difficulty of stent placement. In addition, a smaller stent may be used for the initial passage through to the ductal stenosis site, which could be replaced by a larger stent if required.

This preliminary study has several limitations, which need to be addressed. The current study used an in vitro porcine head model; however, the PLLA stent needs to be examined using an in vivo model. In addition, the composition of the PLLA stent may require further modification and should be investigated further. Furthermore, the degradation time of the PLLA stent was estimated to last for months. Salivary gland ducts secrete enzymes and the constant flow of saliva may have an effect on the degradation of the implanted stent. Therefore, further in vitro analysis examining the degradation rate as well as other physical properties associated with the stent is required. Although there is a general consensus that a stent is used to prevent re-stenosis and for maintaining the opening of the salivary duct after complete sialendoscopy, there is no recommended duration of stent implantation for salivary ductal stenosis. Several studies have demonstrated that the duration of stent placement is usually a minimum of 2-8 weeks (17-19). However, with a biodegradable stent the optimal time could be weeks, months or longer and therefore further investigation is required.

In conclusion, the current study demonstrated that the PLLA biodegradable salivary duct stent had a greater resistance to the collapsing force, compared with commercially available non-biodegradable stents. In addition, the PLLA stent was easily used with current sialendoscopy techniques, allowing accurate stent placement in an animal model with a relatively small ductal lumen.

\section{Acknowledgements}

The authors would like to thank Professor M. Koch for their assistance with the current study.

\section{Funding}

This present study was supported by a grant from the Taipei Medical University Wan-Fang Hospital Research Fund (grant no. 105TMU-WFH-17).

\section{Availability of data and materials}

The datasets used and/or analyzed during the present study are available from the corresponding author on reasonable request.

\section{Authors' contributions}

YD wrote the manuscript and performed the experiments. HT and CS interpreted the data and performed the experiments. $\mathrm{CT}, \mathrm{YW}, \mathrm{CH}$ and $\mathrm{CL}$ performed the experiments and recorded the data. SH designed the study, interpreted the data, supervised the experiments and wrote the manuscript.

\section{Ethics approval and consent to participate}

Not applicable.

\section{Patient consent for publication}

Not applicable.

\section{Competing interests}

The authors declare that they have no competing interests.

\section{References}

1. Maresh A, Kutler DI and Kacker A: Sialoendoscopy in the diagnosis and management of obstructive sialadenitis. Laryngoscope 121: 495-500, 2011.

2. Lempe A, Brehm W and Scharner D: Stent reconstruction of an injured parotid duct in a thoroughbred colt. Vet Surg 41: 536-539, 2012.

3. Eckel HE and Bootz F: Preventive salivary stent use. Laryngorhinootologie 92: 374-375, 2013 (In German).

4. Su CH, Lee KS, Tseng TM and Hung SH: Post-sialendoscopy ductoplasty by salivary duct stent placements. Eur Arch Otorhinolaryngol 273: 189-195, 2016.

5. Huang CH, Hung SH and Su CH: Reply: To PMID 25216563. J Oral Maxillofac Surg 73: 799-801, 2015.

6. Park SJ, Park DW, Kim YH, Kang SJ, Lee SW, Lee CW, Han KH, Park SW, Yun SC, Lee SG, et al: Duration of dual antiplatelet therapy after implantation of drug-eluting stents. N Engl J Med 362: 1374-1382, 2010.

7. Beilvert A, Faure F, Meddahi-Pellé A, Chaunier L, Guilois S, Chaubet F, Lourdin D and Bizeau A: A resorbable shape-memory starch-based stent for the treatment of salivary ducts under sialendoscopic surgery. Laryngoscope 124: 875-881, 2014. 
8. Wang S, Liu Y, Fang D and Shi S: The miniature pig: A useful large animal model for dental and orofacial research. Oral Dis 13: 530-537, 2007.

9. Marchal F, Chossegros C, Faure F, Delas B, Bizeau A, Mortensen B, Schaitkin B, Buchwald C, Cenjor C, Yu C, et al: Salivary stones and stenosis. A comprehensive classification. Rev Stomatol Chir Maxillofac 109: 233-236, 2008.

10. Epker BN: Obstructive and inflammatory diseases of the major salivary glands. Oral Surg Oral Med Oral Pathol 33: 2-27, 1972.

11. Ngu R, Brown J, Whaites E, Drage N, Ng S and Makdissi J: Salivary duct strictures: nature and incidence in benign salivary obstruction. Dentomaxillofacial Radiology 36: 63-67, 2007.

12. Brown AL, Shepherd D and Buckenham TM: Per oral balloon sialoplasty: Results in the treatment of salivary duct stenosis. Cardiovasc Intervent Radiol 20: 337-342, 1997.

13. Nahlieli O, Shacham R, Yoffe B and Eliav E: Diagnosis and treatment of strictures and kinks in salivary gland ducts. J Oral Maxillofac Surg 59: 484-492, 2001

14. Marchal F, Dulguerov P and Lehmann W: Interventional sialendoscopy. N Engl J Med 341: 1242-1243, 1999.

15. Marchal F, Becker M, Dulguerov P and Lehmann W: Interventional sialendoscopy. Laryngoscope 110: 318-320, 2000.

16. Koch M, Iro H and Zenk J: Sialendoscopy-based diagnosis and classification of parotid duct stenoses. Laryngoscope 119: 1696-1703, 2009.
17. Kopeć T, Szyfter W, Wierzbicka M and Nealis J: Stenoses of the salivary ducts-sialendoscopy based diagnosis and treatment. Br J Oral Maxillofac Surg 51: e174-e177, 2013.

18. Koch M, Iro H, Klintworth N, Psychogios G and Zenk J: Results of minimally invasive gland-preserving treatment in different types of parotid duct stenosis. Arch Otolaryngol Head Neck Surg 138: 804-810, 2012.

19. Strychowsky JE, Sommer DD, Gupta MK, Cohen N and Nahlieli O: Sialendoscopy for the management of obstructive salivary gland disease: A systematic review and meta-analysis. Arch Otolaryngol Head Neck Surg 138: 541-547, 2012.

20. Tamai H, Igaki K, Kyo E, Kosuga K, Kawashima A, Matsui S, Komori $\mathrm{H}$, Tsuji $\mathrm{T}$, Motohara $\mathrm{S}$ and Uehata $\mathrm{H}$ : Initial and 6-month results of biodegradable poly-1-lactic acid coronary stents in humans. Circulation 102: 399-404, 2000.

21. Ferdous J, Kolachalama VB and Shazly T: Impact of polymer structure and composition on fully resorbable endovascular scaffold performance. Acta Biomater 9: 6052-6061, 2013.

(i)(3) This work is licensed under a Creative Commons Attribution-NonCommercial-NoDerivatives 4.0 International (CC BY-NC-ND 4.0) License. 